\title{
The profile analysis of attempted-suicide patients referred to Pelonomi Hospital for psychological evaluation and treatment from 1 May 2005 to 30 April 2006
}

E H du Toit, medical student

J M Kruger, medical student

SM Swiegers, medical student

$M$ van der Merwe, medical student

F J W Calitz, BA Hons, MA (Clin Psychol), D Phil

Department of Psychiatry, University of the Free State, Bloemfontein

L Philane, MA (Clin Psychol)

Pelonomi Hospital, Bloemfontein

G Joubert, BA, BSC

Department of Biostatistics, University of the Free State, Bloemfontein

Background. Suicide is an increasing phenomenon worldwide. A suicide occurs every 40 seconds, and there is 1 attempt every 1 to 3 seconds. By 2020, these figures may have doubled. No accurate statistics regarding the occurrence of attempted suicide (or non-fatal suicidal behaviour) in South Africa exist, because there has been no systematic data collection.

Aim. The aim of the study was to determine the profile of patients who had attempted suicide and were referred to Pelonomi Hospital, Bloemfontein, for psychological evaluation and treatment during the period 1 May 2005 to 30 April 2006.

Method. A descriptive, retrospective study was conducted The study population comprised 258 attempted-suicide patients referred to Pelonomi Hospital for psychologica evaluation and treatment. A data form was compiled to transfer the relevant information from patients' clinical files.

Results. The majority of patients were female (68.9\%). The median age was 22 years. The most common method used in suicide attempts was drug overdose $(66 \%)$ - mostly antidepressants $(19.7 \%)$ ) and analgesics (8.2\%). More females than males overdosed on drugs ( $p=0.0103$ ) The main precipitating factors included problematic relationships (55.4\%), financial problems (22.9\%), psychiatric problems (22.1\%), arguments (19.8\%), abuse (emotional, sexual, physical - 18.2\%), low self-esteem/ worthlessness/hopelessness/humiliation (16.7\%), and recent life changes (13.2\%)

Conclusion. The aim of the study was to determine the profile of patients who had attempted suicide. Possible factors associated with suicide attempts in our sample were identified and summarised in the form of a screening checklist. The value of the checklist is that it can be used as a screening method to identify possible suicide risk in patients.

One of the greatest challenges to health professionals is the prediction of suicide. ' Suicide is defined as taking one's own life intentionally. If one does not succeed in ending one's life, the attempt constitutes non-fatal suicide. Non-fatal suicides can be categorised into two groups:

Attempted suicide - not failing deliberately; in other words, those who intended to take their own lives and wished to die. ${ }^{2}$

Parasuicide - failing deliberately; i.e. those who made impulsive suicidal gestures or deliberately harmed themselves, either as a punitive gesture or to draw attention to themselves or to their plight. ${ }^{2}$

According to the World Health Organization's global report on Violence and Health (2002), someone commits suicide every 40 seconds, and 1 attempt is made every 1 to 3 seconds. ${ }^{3}$ By 2020, these figures may have risen to 1 death every 20 seconds and 1 attempt every 1 - 2 seconds. ${ }^{4}$ On average, these statistics point to more people dying per year from suicide than from war, violence, homicide and traffic accidents all together.

Every year in the USA, more than 500000 patients are treated in hospital emergency rooms for attempted suicide, and more than 30000 people succeed in committing suicide. ${ }^{5}$ Suicide is currently the 8 th leading cause of death for the general American population, and the 3rd leading cause of death among teenagers. ${ }^{6}$ Countries in the European 
Union seem to be below the world average of 15.7 per 100000 . Ireland, for instance, has an average suicide rate of 12.9 per 100000 of the population. ${ }^{7}$ South African suicide statistics, at 19 per 100000 of the population, seem to be higher in comparison with industrialised nations. ${ }^{8}$

There are no accurate statistics regarding the occurrence of parasuicide or non-fatal suicidal behaviour in South Africa because there has been no systematic data collection. Information therefore is mostly derived from ad hoc research. These studies, 90 have shown that at least 137860 160000 - or even more - South Africans engage in non-fatal suicidal behaviour every year. Interestingly lalbeit alarming), there are:

- 13333 non-fatal suicide attempts every month

- 3077 per week

- 438 every day

- 18 or more per hour.

According to these figures, it is estimated that, for every fatal suicide, there are at least 20 non-fatal suicide attempts. ${ }^{9}$

The Violence and Injury Mortality Survey of 1999, conducted in 5 South African provinces, found that suicide accounted for about $8 \%$ of all deaths, of which $79 \%$ were of males. ${ }^{11}$

In the pre-Apartheid era, suicidal behaviour was underresearched among the majority of the black population, and lower rates were reported in comparison with other ethnic groups. ${ }^{12}$ This should be taken into account when considering the $58.1 \%$ increase of suicidal behaviour noted among black South Africans over the past decade. ${ }^{13}$

The average age of those who commit suicide in South Africa is 25 years. ${ }^{14} \mathrm{~A}$ third of all suicidal behaviour involves adolescents or children. It should be taken into account that adolescent suicides are under-reported, because families and physicians conceal the true case of death to avoid stigma. Black youths aged 18 years and younger have been identified as a possible high-risk group because they presented as $24.5 \%$ of a total sample of suicidal behaviour cases admitted to a hospital during a study. Of these, $91.3 \%$ were females. ${ }^{15}$

The prevalence of non-fatal suicidal behaviour in South Africa indicates that females have higher rates of suicidal ideation and non-fatal suicidal behaviour than males. ${ }^{9}$ However, non-fatal suicide attempts by males may be under-reported because of the stigma associated with such behaviour. ${ }^{16}$
The most frequently used method for attempting suicide is selfpoisoning. Other common methods include cutting, hanging, firearms, gassing and burning. Men are more likely to use overtly violent methods, whereas women prefer less violent means such as self-poisoning by drug overdose. ${ }^{17}$ Painkillers, tranquillisers and antidepressants are commonly used for overdosing, followed by poison and other utility products. ${ }^{18}$

The presence of certain risk factors may indicate that a person is considering suicide. These factors can be demographic, medical and psychosocial (which may include psychiatric disorders). ${ }^{19}$ The risk of suicide increases if a person is widowed, divorced or single. The decision to commit suicide may also be influenced by a lack, or recent loss, of social support. Another risk factor is recent unemployment; a sudden decline in social or economic status plays a major role in committing suicide..$^{20}$

The following factors have been associated with increased suicide risk: the presence of illness (physical or psychiatric), ${ }^{21}$ alcohol or drug abuse, ${ }^{22}$ previous suicide attempts, and the presence of a lethal weapon (e.g. a firearm) or another source of self-harm..$^{20}$

Psychosocial factors are especially prone to elicit suicidal behaviour in adolescents. These include family problems, behavioural problems, social problems and recent exposure to a suicide attempt. Family problems can comprise parental absence, parental abuse, parental substance abuse, a family history of suicide, and conflict with parents. Impulsiveness, explosive temper, attention deficit hyperactivity disorder, depression and bipolar disorder are all classified as behavioural problems. Social problems may include academic problems, conduct problems or disciplinary crises, humiliation, or marriage with socioeconomic problems. ${ }^{23}$

In summary, it is evident that suicide is a worldwide problem. There are no accurate statistics in South Africa regarding the behaviour surrounding parasuicide or attempted suicide because there has been no systematic data collection. Information is therefore mostly derived from ad hoc research. For this reason, there was a need to determine the demographic profile, the nature of suicide attempts, and possible risk factors associated with attempted suicide.

\section{Objective}

The aim of this study was to determine the profile of attempted suicide patients who were referred to Pelonomi Hospital for 
psychological evaluation and treatment from 1 May 2005 to 30 April 2006.

Specific objectives were to determine:

- the demographic profile of the participants

- the nature of the suicide attempts, and

- possible risk factors associated with non-fatal suicides.

\section{Methods}

\section{Study design}

The study was a descriptive, retrospective study.

\section{Study population}

All attempted suicide patients referred to Pelonomi Hospital's clinical psychologists for psychological evaluation and treatment during the period of 1 May 2005 to 30 April 2006 were included - a total of 259 patients.

\section{Measurements}

A computerised data form was compiled that was used to record relevant information from the patients' clinical files. After receiving written permission from the Chief Executive Officer, the files were obtained from clinical psychologists at Pelonomi Hospital. The researchers themselves completed the data forms according to the contents of the patients' files.

\section{Pilot study}

A pilot study was conducted using 20 files of patients referred during 2005 and 2006 . The data forms were adjusted after the pilot study. Data obtained from these files were included in the main study.

\section{Data analysis}

Analysis was done by the Department of Biostatistics, University of the Free State. The data were summarised as frequencies and percentages (categorical variables), and means or percentiles (numerical variables).

\section{Ethics}

The study was approved by the Ethics Committee, Faculty of Health Sciences, University of the Free State. Permission was obtained from the Chief Executive Officer of Pelonomi Hospital. Patient names were not noted on the data forms, and all data were treated confidentially.

\section{Results and discussion}

\section{Demographic information}

The majority (68.9\%) of the attempted suicide patients was female. This finding was expected and correlates with other studies. 9,15,17 One of the reasons for this finding could be that males succeed in their attempts more often because they use more violent and lethal methods. ${ }^{16}$ Another reason may be that males under-report their attempts, because of the stigma associated with such behaviour. ${ }^{19}$ It could also be that females have a greater suicidal inclination - and therefore make more frequent suicide attempts.

The age group with the highest number of attempted suicides was that between 18 and 31 years. The median was 22 years. This finding is closely related to the average age 125 years) of those who commit suicide in South Africa. ${ }^{14,22}$ The youngest was a 7-year-old boy, and the oldest an 87-yearold man. There was a significant difference in age between males and females (Table I) ( $p=0.0021$ ), with females making their suicide attempts at a younger age. This reflects the higher tendency of females attempting suicide, possibly as a result of their being more sensitive to life stressors.

\begin{tabular}{llll}
\multicolumn{4}{l}{ Table I. Age of attempted suicide cases } \\
\hline Gender & Lower quartile & Median & Upper quartile \\
\hline Male & 21 & 26.5 & 34 \\
Female & 17 & 21 & 30 \\
\hline
\end{tabular}

Of all the attempted suicide patients in this study, 49 (19\%) were married, 162 (62.8\%) were not married, and in 37 (14.3\%) of cases marital status was not mentioned. Among the unmarried group, $99(38.4 \%)$ were single and 63 (24.4\%) were engaged.

\section{Nature and frequency of the suicide attempts}

The graph in Fig. 1 shows the number of attempted suicides during the review period.

Most of the attempted-suicide patients in 2005 were admitted in May (26), followed by November (25), August (23) and June (20). The increase in November might have been because of exams, work or other year-end stressors. In 2006, most attempted-suicide patients were admitted in January (44), followed by February (33) and March (29). The reason for the high number of admissions at the beginning of 2006 may be associated with increased levels of stress after 


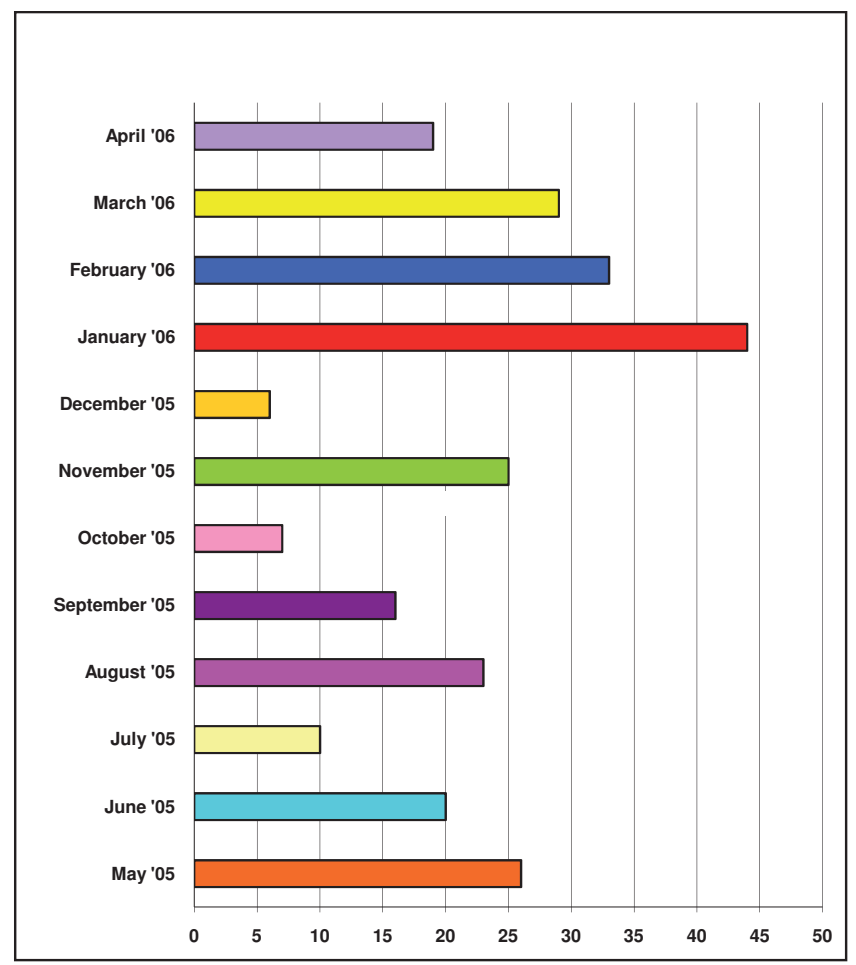

Fig. 1. Number of attempted suicide patients admitted monthly.

the holiday and festive season, less support from the family, loneliness and adaptation challenges of the New Year.

Twenty-two patients (8.5\%) had known previous suicide attempts.

The findings concerning the methods used in attempted suicides are presented in Fig. 2. Self-poisoning was used in 234 cases (90.7\%). Most (183-66\%) of the participants overdosed using prescription medication, followed by the use of household chemicals in 33 cases (12\%) and other chemicals in 18 cases (7\%). Five participants (2\%) used a method other than self-poisoning. In 35 cases (13.7\%), the method of suicide attempt was not mentioned.

Most (19.7\%) of the participants who overdosed used antidepressants. Analgesics were used in $8.2 \%$ of instances. The most commonly used household chemicals for self-

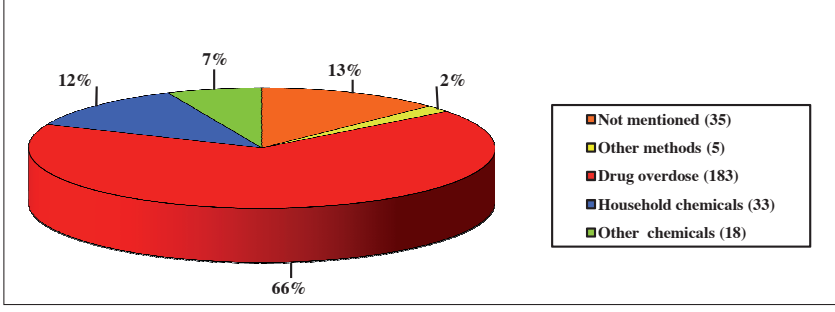

Fig. 2. Methods used in attempted suicides. poisoning were Jik (5 cases - 15.2\%) and paraffin ( 12 cases - 36.4\%). More females than males overdosed on drugs in their suicide attempt $(p=0.0103)$. The male-to-female ratio was 1:14 where analgesic overdose was used ( $p=0.0423)$.

\section{Possible risk factors associated with parasuicide/attempted suicide}

The precipitating factors (in numerical order) found in the study were problematic relationships (55.4\%); financial problems (22.9\%); psychiatric problems (22.1\%); arguments (19.8\%); abuse (18.2\%); feelings of low self-esteem, worthlessness, hopelessness or humiliation (16.7\%); recent life changes (13.2\%); unstable family life (9.3\%); lack of social support (9.3\%); scholastic problems (9.3\%); isolation/ rejection (8.9\%); chronic medical condition (7.8\%); substance use or abuse (7.1\%); pregnancy (5.4\%); imprisonment and involvement in crime $(2.7 \%)$; problems at work (2.3\%) and childhood trauma (2.3\%). Many of the participants had more than one precipitating factor. For the purpose of this paper, only those risk factors which occurred in 10\% or more of the participants are discussed.

The problematic relationships experienced by about 55\% (143) of the total number of patients were as follows: relationship problems with family members - $51.7 \%$, with spouses - $20.3 \%$, and with boyfriend/girlfriend or fiancé - 15.4\%. Problematic relations with family members included parental figures (71.6\%), siblings $(9.5 \%)$ and children (8. $1 \%)$.

Financial problems (unemployment, poverty, debt) were present in 59 patients (22.9\%), of whom 23 (39\%) were unemployed. This finding is not surprising, taking into account that the national unemployment rate is $41 \% .{ }^{24}$

The precipitating factors in 57 (22.1\%) patients were psychiatric in nature. Most of them (50.9\%) complained of depression, 4 experienced hallucinations, and 3 suffered from insomnia. Another 25 (9.7\%) patients had suicidal ideation. There was also a strong correlation between antidepressant overdose and individuals suffering from depression ( $p=0.0609$ ). Eighteen (7\%) patients experienced fear or anxiety: 3 had had threats that they would be assaulted or killed, and 1 was accused by a drug dealer of stealing money. The others had nonspecific causes of fear and anxiety.

Another important precipitating factor was reflected in the fact that 51 (19.8\%) patients had had an argument prior to 
their suicide attempt: 40 (78.4\%) with a family member, 20 with a parental figure, 5 with siblings, 10 with their spouse, and 8 with the person with whom they were involved in a relationship.

Abuse contributed to 47 (18.2\%) attempted suicides. Twenty-seven patients were in an abusive relationship, 11 experienced problems at home (domestic violence, fighting, conflict between parents) and 3 had been raped. Two had been assaulted and 2 bullied/involved in a fight at school or were 'overly controlled' by someone.

Substance use/abuse contributed to 44 (7.1\%) non-fatal suicides. Seventeen patients abused alcohol, while only 8 abused drugs. Nine patients had a parent or parents who abused alcohol and/or drugs. Ten had a partner or a family member who abused alcohol or drugs. The male-to-female ratio for alcohol abuse was 1 1:6 ( $p=0.002)$. More males than females were under the influence of a substance at the time of the suicide attempt ( $p=0.0017)$.

Forty-three (16.7\%) patients had low self-esteem or experienced feelings of worthlessness, hopelessness or humiliation, of whom 12 had a cheating partner, 8 were affected by their parents' divorce, 6 were overwhelmed by children/lack of discipline in children, 2 had had a relationship break-up, 1 had been recently declared unfit for work on medical grounds, and 1 was humiliated.

Thirty-four (13.2\%) patients had experienced a recent loss, of which 23 were the recent death of a first-degree relative, partner or friend. Other recent losses included recent migration (4), miscarriage (3), abortion (2), bereavement (one young boy's dog died) and loss of job on medical grounds (1).

\section{Conclusion}

The aim of the study was to determine the profile of patients who presented with attempted suicide and were referred to Pelonomi Hospital for psychological evaluation and treatment from 1 May 2005 to 30 April 2006.

Of particular interest in our study was the identification of the main predisposing factors in patients presenting with attempted suicide. These factors are summarised in Table II, which could be used as a screening method to identify possible suicide risk in patients.

Although this study produced significant findings the results should be interpreted with great care, especially as far as

\begin{tabular}{|c|c|c|}
\hline Risk factors & Present & Not present \\
\hline \multicolumn{3}{|l|}{ Female } \\
\hline \multicolumn{3}{|l|}{ Single } \\
\hline \multicolumn{3}{|l|}{$18-31$ years } \\
\hline \multicolumn{3}{|l|}{ Problematic relationship } \\
\hline \multicolumn{3}{|l|}{$\begin{array}{l}\text { Abuse (emotional, } \\
\text { sexual, physical) }\end{array}$} \\
\hline \multicolumn{3}{|l|}{$\begin{array}{l}\text { Recent life changes } \\
\text { (death, work, migration) }\end{array}$} \\
\hline \multicolumn{3}{|l|}{$\begin{array}{l}\text { Financial problems } \\
\text { (unemployment, debt) }\end{array}$} \\
\hline \multicolumn{3}{|l|}{$\begin{array}{l}\text { Drug overdose (antide- } \\
\text { pressants and } \\
\text { analgesics) }\end{array}$} \\
\hline \multicolumn{3}{|l|}{$\begin{array}{l}\text { Low self-esteem, worth- } \\
\text { lessness, hopelessness, } \\
\text { humiliation }\end{array}$} \\
\hline \multicolumn{3}{|l|}{ Recent argument } \\
\hline $\begin{array}{l}\text { Psychiatric problems } \\
\text { (depression) }\end{array}$ & & \\
\hline
\end{tabular}

generalisation is concerned; for example, only patients referred to Pelonomi Hospital were included in the study. However, the study should not be under-estimated, because it not only contributes to important academic data in this field, but also provides information on demographic profile, nature of suicide attempts, and possible factors contributing to attempted suicide.

\section{References}

1. Cassels C, Paterson B, Dowding D, Morrison R. Long- and short-erm risk factors in the prediction of inpatient suicide. The Journal of Crisis Intervention and Suicide Prevention 2005; 26(2): 53-63.

2. Mashego B, Peltzer K, Williamson G, Setwaba M. A Suicide Preventing Manual for Suicidal Learners in School. Mafikeng: North West Department of Education, 2006: 8.

3. Krug EC, Dahlbury LL, Mercy JA, Zwi AB, Lozano R. World Report on Violence and Health. Geneva: World Health Organization, 2002.

4. Bertolote JM. Suicide in the world: An epidemiological overview 1959-2000. In Wasserman D, ed. Suicide: An Unnecessary Death. London: Martin Dunitz, 2001 3-10.

5. Davison GC, Neale JM. Abnormal Psychology. New York: John Wiley \& Son, 1998 250-251

6. Nevid JS, Rathus SA, Greene B. Abnormal Psychology in a Changing World. New York: Prentice Hall, 2003: 256

7. Health Service Executive, National Suicide Review Group, Department of Health and Children. Reach Out: National Strategy for Action on Suicide Prevention for 2005 to 2014. Dublin, Ireland: Health Service Executive, 2005: 9.

8. Schlebusch L. Suicidal Behaviour in South Africa. Pietermaritzburg: University of KwaZulu-Natal Press, 2005

9. Schlebusch L. Current perspectives on suicidal behaviour in South Africa. In: Suffle S, Van Niekerk A, Duncan D, eds. Crime, Violence and Injury Prevention in South Africa: Developments and Challenges. Tygerberg: Medical Research Council-UNISA Crime, Violence and Injury Lead Programme, 2004: 9-21.

10. Schlebusch L. An overview of suicidal behaviour in South Africa as we enter the new millennium. In: Schlebusch L, Bosch BA, eds. Suicidal Behaviour4: Proceedings of the Fourth Southern African Conference on Suicidology. Durban: Department of Medically Applied Psychology, Faculty of Medicine, University of Natal, 2000: 3-1 1.

1 1. World Health Organization. Report on a workshop on suicide prevention for countries in the African region. Geneva: Department of Mental Health, WHO, 1999. 
12. Schlebusch L, Bosch BA, eds. Suicidal Behaviour 4: Proceedings of the Fourth Southern African Conference on Suicidology. Durban: Department of Medically Applied Psychology, Faculty of Medicine, University of Natal, 2000.

13. Schlebusch L, Vawda N, Bosch BA. Suicidal behaviour among black South Africans. Crisis 2003; 24(1): 24-28

14. Deonarain M, Pillay BJ. A study of parasuicide behaviour at the Chris Hani Baragwanath Hospital. In: Schlebusch L, Bosch BS, eds. Suicidal Behaviour 4: Proceedings of the Fourth Southern African Conference on Suicidology. Durban: Department of Medically Applied Psychology, Faculty of Medicine, University of Natal, 2000: 11 2-127.

15. Schlebusch L, Bosch BA. Suicidal Behaviour 4. 1st ed. Durban: Department of Medically Applied Psychology, School of Family and Public Health, Nelson R Mandela School of Medicine, 2000: 5-8.

16. Canetto SS, Sakinofsky I. The gender paradox in suicide. Suicide and Life-Threatening Behaviour 1998; 28: 1-23.

17. Nevid JS, Rathus SA, Greene B. Abnormal Psychology in a Changing World. New York: Prentice Hall, 2003: 257.
18. Van Elfen J. Dokter in die Huis. Cape Town: Tafelberg Uitgewers, 2001 : 545-546.

19. White D. Emergency psychiatry. in: Robertson B, Allwood C, Gagiano C, eds Textbook of Psychiatry for Southern Africa. Cape Town: Oxford University Press South Africa, 2001: 373-374.

20. Risk factors for suicide in adults. Houston, USA: Institute for Algorithmic Medicine http://www.medal.org.html (accessed 17 February 2006).

21. Erasmus JAK. 'n Klinies diagnostiese ontleding van 'n groep persone wat een of meer pogings tot selfmoord aangewend het. Literatuur-oorsig. MA thesis, University of Pretoria, 1970: 16-54.

22. Buglass D, Holding T, Kennedy PF, Kreitman N, Philip AE. Parasuicide. In: Kreitman N, ed. The Epidemiology of Parasuicide. 1st ed. London: John Wiley \& Sons, 1977 $12-40$.

23. Risk factors for suicide by adolescents. Houston, USA: Institute for Algorithmic Medicine. http://www.medal.org.html (accessed 17 February 2006).

24. Census 2001. Pretoria: Statistics South Africa, 2001 